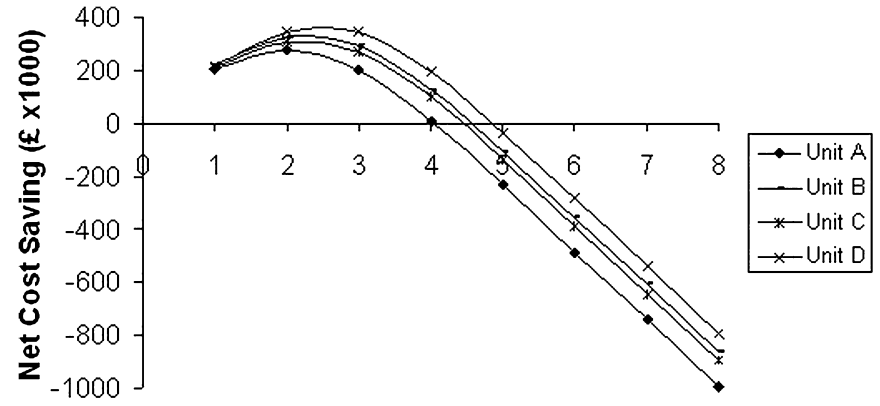

Number of Beds in Weaning Unit

Abstract S9 Figure 1 Modelling net cost saving of establishing a weaning unit by varying capacity from 1 to 8 beds.

Conclusion PMV patients use $25 \%$ of ICU bed-days in our region. Establishing a 3-bed weaning unit could lead to a reduction of 800 ICU bed-days, a net annual cost saving of $£ 340000$, and acceptable occupancy $(70 \%)$ and refusal $(30 \%)$ rates. Establishing such a unit would be feasible in our health board region.

\section{S10 IS IT COST-EFFECTIVE TO REPLACE NURSES WITH LAY ASTHMA EDUCATORS IN PRIMARY CARE?}

doi:10.1136/thx.2010.150912.10

${ }^{1} \mathrm{~N} J$ Roberts, ${ }^{1} \mathrm{~K}$ Boyd, ${ }^{1} \mathrm{~A}$ Briggs, ${ }^{2} \mathrm{~A} \mathrm{~L}$ Caress, ${ }^{3} \mathrm{M} \mathrm{R}$ Partridge. ${ }^{1}$ Health Economics Appraisal Team, Public Health and Health Policy, University of Glasgow, Glasgow, UK; ${ }^{2}$ Nursing, Midwifery and Social Work, University of Manchester, Manchester, UK; ${ }^{3} \mathrm{NHLI}$ Division at Charing Cross, Imperial College London, London, UK

Introduction Regular review of those with asthma and support for self-management is promoted in guidelines and encouraged by the Quality Outcomes Framework. Reasons for non-implementation include lack of time and training. A large randomised controlled trial in primary care suggested that need for unscheduled health care was similar if patients were reviewed and offered self management support by a trained lay educator compared to practice nurses. ${ }^{1}$

Methods A cost-effectiveness analysis was undertaken using the trial data. The cost of delivery for the intervention incorporated training and consultations. The measure of effectiveness was frequency of unscheduled healthcare which has also been costed.

Results One year intention to treat data $(n=418)$ showed that $29 \%$ $(61 / 205)$ of patients in the nurse group required unscheduled healthcare (177 events) compared with $30.5 \%(65 / 213)$ in the lay group (178 events), that is, there was no statistical difference in effect between the groups. Assigning a cost to this measure of effectiveness (unscheduled healthcare) provides $£ 161$ for nurses and $£ 135$ for lay trainers, that is, no significant difference (mean $£ 26$, (95\% CI $-95.61,146.69, \mathrm{p}=0.679)$ ). With regards to the costs of delivery, there was no significant difference between the two arms (mean difference $£-1.61(95 \% \mathrm{CI}-6.01,2.77, \mathrm{p}=0.4704)$ ). While the training costs for the lay trainers were greater than nurses ( $£ 35 \mathrm{vs}$ $£ 18$, respectively, per patient, $\mathrm{p}<0.001$ ), the consultation costs for lay trainers were lower than for nurses ( $£ 8$ per patient vs $£ 24$, $\mathrm{p}<0.001)$. The total costs, consisting of delivery and the measured outcome (unscheduled healthcare), were $£ 203$ per patient for the nurse arm vs $£ 179$ for lay trainers (mean difference $£ 24$, (95\% CI -97.15, 144.99, $\mathrm{p}=0.698)$ ).

Conclusion There was no significant difference in cost of delivery or in the effectiveness of the intervention between the two arms in this trial. It may be inappropriate to conclude that the intervention is not worthwhile as contracting lay trainers full-time rather than part-time would have made full use of the cost of their training, reducing the cost per patient and improving efficiency.
Funding Supported by the BUPA Foundation.

\section{REFERENCES}

1. Partridge MR, Caress AL, Brown C, et al. Can lay people deliver asthma selfmanagement education as effectively as primary care based practice nurses? Thorax 2008;63:778-83.

\section{S11 THE SOUTH EAST ESSEX (SEE) MODEL OF INTEGRATED COPD CARE AND OUIP (OUALITY INNOVATION AND PRODUCTIVITY) IMPROVEMENTS}

doi:10.1136/thx.2010.150912.11

${ }^{1} \mathrm{~A}$ G Davison, ${ }^{2} \mathrm{E}$ Paddison, ${ }^{2} \mathrm{C}$ Hanna, ${ }^{3} \mathrm{~S}$ Taylor. ${ }^{1}$ Southend University Hospital, Southend on Sea, UK; ${ }^{2}$ South East Essex PCT, Southend on Sea, UK; ${ }^{3}$ Southend PBC Group, Southend on Sea, UK

The coalition Government has announced there should be $£ 20$ billion saving over the next financial cycle in the health budget, and the QUIP (Quality, Innovation and Productivity) agenda is at the heart of this. The SEE model is an ongoing project of integrating COPD care across primary and secondary providers. A robust local network is at the centre of the project which includes increased Consultant community care (real and virtual), education of staff at the University of Essex, Hospital at Home, improved communication, increased community rehabilitation, community spirometry, improved pathways, self-management plans, oxygen alert cards, dedicated oxygen service and involvement of Breathe Easy. We have reviewed our data to see if productivity has improved in line with the QUIP agenda.

Results (See Abstract S11 Table 1) Oxygen provision has been reviewed in a three-step process starting with the highest tariffs and extending to all patients on oxygen resulting in $£ 250000$ saving per year.

\section{Abstract S11 Table 1}

\begin{tabular}{|c|c|c|c|}
\hline \multicolumn{4}{|c|}{ Summary of reduction in emergency COPD admissions, bed days and cost } \\
\hline Financial year & $07 / 08$ & $08 / 09$ & $09 / 10$ \\
\hline Number COPD admissions & 909 & 841 & 740 \\
\hline Number COPD bed days & 6969 & 5925 & 5327 \\
\hline Cost as per $2009 / 10 \mathrm{PbR}$ & $£ 2141259$ & $£ 2067171$ & $£ 1781052$ \\
\hline \multicolumn{4}{|c|}{$\begin{array}{l}\text { Reduced new (NP) to follow-up (FU) rations in respiratory outpatients. Indicates high } \\
\text { proportion of follow-up occurring in the community. }\end{array}$} \\
\hline Financial year & $07 / 08$ & $08 / 09$ & $09 / 10$ \\
\hline $\mathrm{NP} / \mathrm{FU}$ ratio & 2.95 & 2.9 & 2.7 \\
\hline
\end{tabular}

Conclusion Integrated services for COPD can bring care closer to home produce reduced admissions, reduced NP/FU ratios and saving on oxygen. Integrated services have achieved savings of at least $£ 650000$ per annum and this is line with the QUIP agenda.

\section{S12 PRE-CLINIC TELEPHONE CONSULTATIONS: A COSTING STUDY}

doi:10.1136/thx.2010.150912.12

${ }^{1} \mathrm{~L}$ O'Byrne, ${ }^{2} \mathrm{~N}$ J Roberts, ${ }^{2} \mathrm{~K}$ Boyd, ${ }^{2} \mathrm{~A}$ Briggs, ${ }^{1} \mathrm{M}$ R Partridge. ${ }^{1} \mathrm{NHLI}$ Division at Charing Cross Hospital, Imperial College London, London, UK; ${ }^{2}$ Health Economics Appraisal Team, Public Health and Health Policy, University of Glasgow, Glasgow, UK

Study of the taking of a patients' history by telephone prior to clinic attendance and co-ordinating investigations for new respiratory patients showed a reduction in hospital attendances with no 